\title{
Intercalibrating Microwave Satellite Observations for Monitoring Long-Term Variations in Upper- and Midtropospheric Water Vapor*
}

\author{
Eui-SeOK CHung AND BRIAN J. SODEN \\ Rosenstiel School of Marine and Atmospheric Science, University of Miami, Miami, Florida \\ VIJU O. JOHN \\ Met Office Hadley Centre, Exeter, United Kingdom
}

(Manuscript received 3 January 2013, in final form 24 May 2013)

\begin{abstract}
This paper analyzes the growing archive of $183-\mathrm{GHz}$ water vapor absorption band measurements from the Advanced Microwave Sounding Unit B (AMSU-B) and Microwave Humidity Sounder (MHS) on board polar-orbiting satellites and document adjustments necessary to use the data for long-term climate monitoring. The water vapor channels located at $183.31 \pm 1 \mathrm{GHz}$ and $183.31 \pm 3 \mathrm{GHz}$ are sensitive to upper- and midtropospheric relative humidity and less prone to the clear-sky sampling bias than infrared measurements, making them a valuable but underutilized source of information on free-tropospheric water vapor. A method for the limb correction of the satellite viewing angle based upon a simplified model of radiative transfer is introduced to remove the scan angle dependence of the radiances. Biases due to the difference in local observation time between satellites and spurious trends associated with satellite orbital drift are then diagnosed and adjusted for using synthetic radiative simulations based on the Interim European Centre for Medium-Range Weather Forecasts Re-Analysis (ERA-Interim). The adjusted, cloud-filtered, and limbcorrected brightness temperatures are then intercalibrated using zonal-mean brightness temperature differences. It is found that these correction procedures significantly improve consistency and quantitative agreement between microwave radiometric satellite observations that can be used to monitor upper- and midtropospheric water vapor. The resulting radiances are converted to estimates of the deep-layer-mean upper- and midtropospheric relative humidity, and can be used to evaluate trends in upper-tropospheric relative humidity from reanalysis datasets and coupled ocean-atmosphere models.
\end{abstract}

\section{Introduction}

Upper-tropospheric water vapor accounts for a tiny fraction of the total water vapor mass due to the exponential decrease of saturation water vapor pressure with altitudes. However, because the trapping of terrestrial longwave radiation is proportional to the logarithm of water vapor concentration (Held and Soden 2000), the small amounts of water vapor in the upper

\footnotetext{
* Supplemental information related to this paper is available at the Journals Online website: http://dx.doi.org/10.1175/ JTECH-D-13-00001.s1.

Corresponding author address: Eui-Seok Chung, Rosenstiel School of Marine and Atmospheric Science, University of Miami, 4600 Rickenbacker Causeway, Miami, FL 33149.

E-mail: echung@rsmas.miami.edu
}

and midtroposphere can exert significant radiative impacts (Held and Soden 2000; Allan et al. 2003; Sherwood et al. 2010). Furthermore, the fact that climate models project amplified upper-tropospheric moistening in response to the surface warming induced by the increase of anthropogenic greenhouse gases emphasizes the importance of long-term monitoring of upper-tropospheric water vapor for the detection and attribution of climate change (e.g., Soden et al. 2005). Therefore, it is important to produce an accurate, continuous observational record of upper-tropospheric water vapor in order to better understand the characteristics of water vapor feedback and to assess the fidelity of climate models in depicting the distribution and variation of water vapor in the upper troposphere (e.g., Bates and Jackson 2001; Bates et al. 2001; Soden et al. 2005; John and Soden 2007).

Since the end of the 1970s, the High Resolution Infrared Radiation Sounder (HIRS) version 2 (HIRS/2) 
on board the National Oceanic and Atmospheric Administration (NOAA) operational polar-orbiting satellites has been taking measurements of the $6.7-\mu \mathrm{m}$ water vapor channel radiances that are closely associated with upper-tropospheric water vapor (Soden and Bretherton 1993). These infrared measurements have provided a valuable tool for monitoring long-term changes in uppertropospheric water vapor and its impact on the climate system (e.g., Bates et al. 1996; Bates and Jackson 2001; Bates et al. 2001; Soden et al. 2005; Shi and Bates 2011). However, the shift of central wavelength from $6.7(\mathrm{HIRS} / 2)$ to $6.5 \mu \mathrm{m}(\mathrm{HIRS} / 3)$ has caused the end of HIRS/2 upper-tropospheric water vapor record in the mid-2000s, requiring elaborate efforts to extend the HIRS/2 record by correcting the biases due to the change in spectral characteristics (e.g., Cao et al. 2005, 2009; Shi et al. 2008; Shi and Bates 2011).

The other potential source of continuous uppertropospheric water vapor record is underutilized (in the context of climate studies) microwave measurements from the Special Sensor Microwave Water Vapor Sounder (SSM/T-2), Advanced Microwave Sounding Unit B (AMSU-B), and Microwave Humidity Sounder (MHS) on board polar-orbiting satellites. These microwave instruments have a $183.31 \pm 1 \mathrm{GHz}$ channel whose spectral characteristics are comparable to those of the 6.7- $\mu \mathrm{m}$ channel (e.g., Chung et al. 2011). In addition, the $183.31 \pm 1-\mathrm{GHz}$ channel radiances are less prone to the clear-sky sampling bias since microwave measurements are less affected by clouds compared to infrared measurements (e.g., Allan and Ringer 2003; Buehler et al. 2007, 2008; Sohn and Bennartz 2008; Chung et al. 2011; John et al. 2011). Another advantage is that the spectral characteristics of the $183.31 \pm 1 \mathrm{GHz}$ channel are approximately identical between these microwave instruments. As a result, the $183.31 \pm 1 \mathrm{GHz}$ channel measurements can be used not only to assess the stability of the HIRS record for the HIRS transition period, but also to generate an independent dataset of upper-tropospheric water vapor for climate studies.

However, various factors may induce observational biases between instruments on different satellites. For example, Fig. 1 compares tropical $\left(30^{\circ} \mathrm{S}-30^{\circ} \mathrm{N}\right)$-mean $183.31 \pm 1 \mathrm{GHz}$ channel brightness temperatures of AMSU-B for $N O A A-15,-16$, and -17 , and MHS for NOAA-18 and Meteorological Operation-A (MetOp-A). Although the spectral characteristics are very similar between the microwave instruments on different satellites, distinct discrepancies are observed for both ascending and descending nodes. In particular, time series of NOAA-15 and NOAA-16 exhibit a positive trend in contrast to the other satellites that do not show a noticeable trend. The bottom panel shows temporal variations of the difference between two nodes (ascending node minus descending node). While the differences are negative in the cases of $N O A A-17$ and $M e t O p$ - $A$, the tropical upper troposphere tends to be more humid for the descending node for NOAA-16 and NOAA-18. The magnitude of the difference between the two nodes is generally stable with time for more recent satellites (i.e., $N O A A-17$, $N O A A-18$, and $M e t O p-A$ ). On the other hand, NOAA-15 shows a clear divergence between the ascending and descending nodes. These intersatellite discrepancies indicate the necessity of bias corrections and intersatellite calibrations.

Given the fact that upper-tropospheric humidity and the resulting radiances exhibit noticeable diurnal variations (e.g., Chung et al. 2007, 2009; Eriksson et al. 2010), differences in the equatorial local crossing time between the satellites with the microwave instruments will induce intersatellite discrepancies. Moreover, these satellites may drift away from their nominal equatorial local crossing time at launch. Since observed radiances increase or decrease depending on the observation times in the diurnal cycle, diurnal sampling biases associated with the orbital drift may result in a spurious long-term trend (e.g., Mears et al. 2003; Jackson and Soden 2007; Mears and Wentz 2009). Therefore, this study aims to detect and correct these biases in the $183.31 \pm 1 \mathrm{GHz}$ channel radiances of AMSU-B and MHS in order to generate a homogenized upper-tropospheric water vapor dataset with a long-term stability. The rectification and intersatellite calibration of SSM/T-2 measurements are deferred because of the lack of calibration information in the 2000s. In addition, the AMSU-B and MHS $183.31 \pm 3 \mathrm{GHz}$ channel observations will be analyzed to produce a continuous dataset of midtropospheric water vapor suitable for climate studies.

\section{Satellite-based microwave radiometer observations}

Satellite-based radiance measurements of the $183-\mathrm{GHz}$ strong water vapor absorption band began in 1992 with the launch of the Defense Meteorological Satellites Program (DMSP)-F11 satellite carrying SSM/T-2. While the SSM/T-2 measurements have continued to succeed DMSP satellites $(F 12, F 14$, and F15), the calibration information required for converting raw count to brightness temperature is not evident in the 2000s. Therefore, we first examine and intercalibrate radiance measurements from the other two microwave humidity sounders, AMSU-B and MHS, which have very similar spectral characteristics to SSM/T-2.

The AMSU-B is a cross-tracking radiometer with three water vapor channels $(183.31 \pm 1 \mathrm{GHz}, \pm 3 \mathrm{GHz}$, 

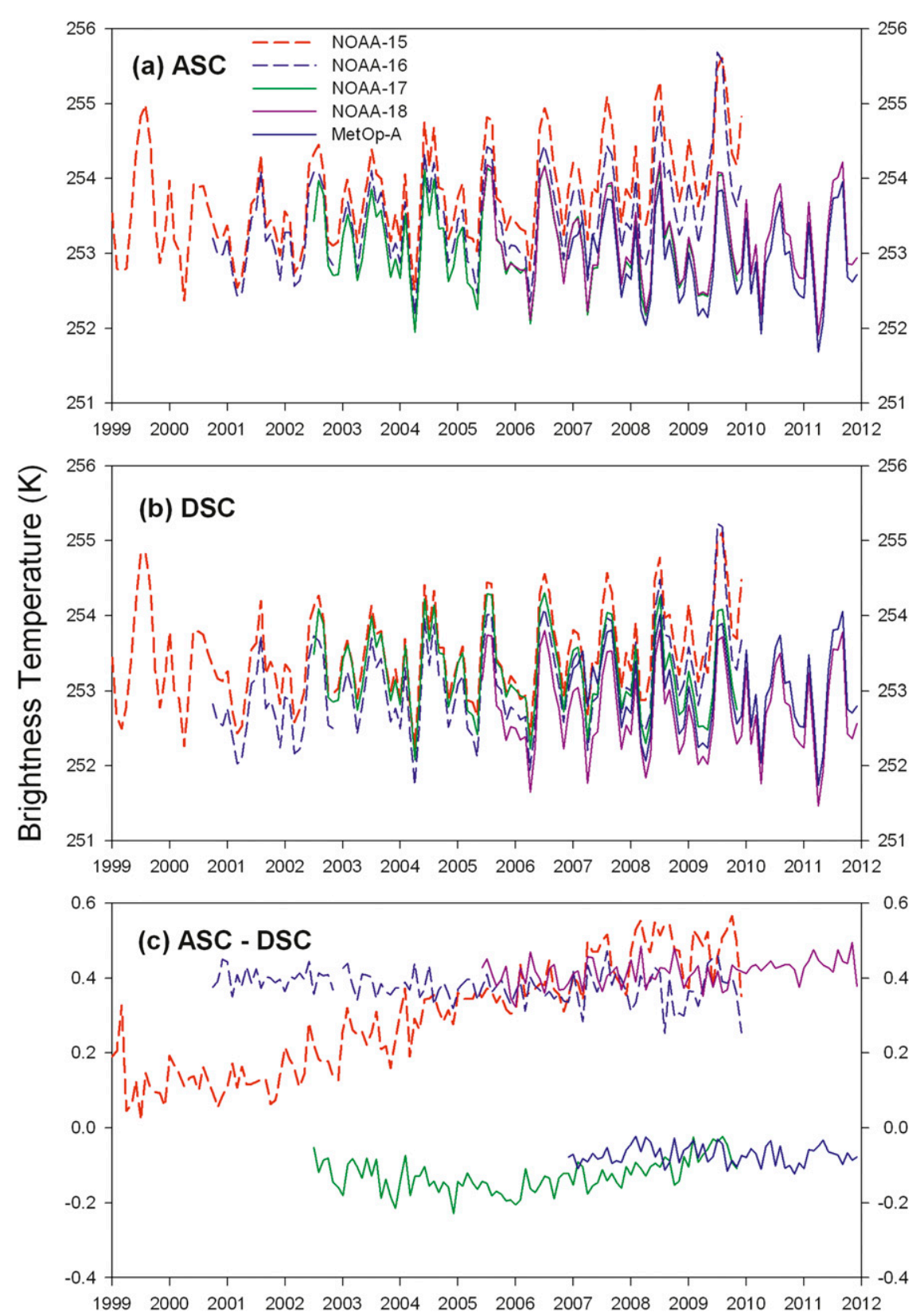

FIG. 1. Time series of the tropical-mean $183.31 \pm 1 \mathrm{GHz}$ channel brightness temperature for polar-orbiting satellites with microwave humidity sounder, AMSU-B (NOAA-15, -16, and -17) and MHS (NOAA-18 and MetOp-A): (a) ascending node, (b) descending node, and (c) difference between ascending and descending nodes.

and $\pm 7 \mathrm{GHz}$ ) along with two window channels. Although the location of the monitored atmospheric layer depends upon the exact nature of the temperature and humidity profiles, the three water vapor channels are sensitive to relative humidity in the upper, mid-, and lower troposphere, respectively (e.g., Buehler and John 2005). Each scan line of AMSU-B consists of 90 footprints between $48.95^{\circ}$ and $-48.95^{\circ}$ about the nadir, with a swath width of $\sim 2300 \mathrm{~km}$. The footprint size is $\sim 20 \times$ $16 \mathrm{~km}^{2}$ for the innermost scan positions, and increases to $64 \times 27 \mathrm{~km}^{2}$ for the outermost scan positions (John and Buehler 2004). The nominal noise equivalent temperatures are $1.06,0.70$, and $0.60 \mathrm{~K}$ for $183.31 \pm$ $1 \mathrm{GHz}, \pm 3 \mathrm{GHz}$, and $\pm 7 \mathrm{GHz}$ channels, respectively. Three NOAA polar-orbiting satellites (NOAA-15, -16, and -17) carry the AMSU-B radiometer. 
Transmittance Difference (HIRS/3 - HIRS/2)

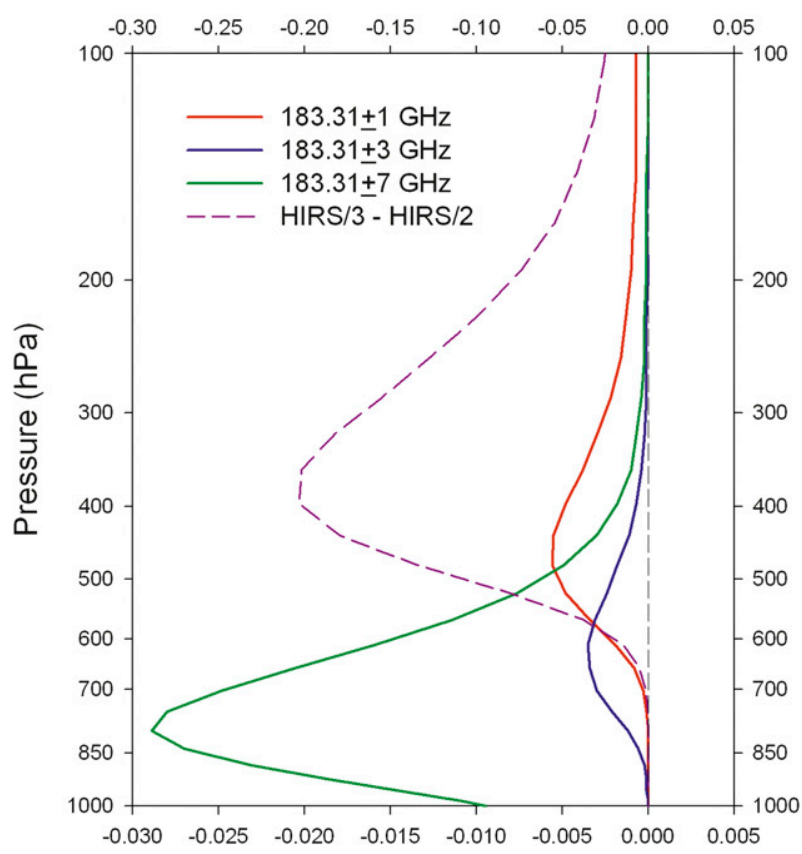

Transmittance Difference (MHS - AMSU-B)

FIG. 2. Comparison of the $183-\mathrm{GHz}$ water vapor channel transmittances for an atmospheric profile between AMSU-B and MHS. In addition, the HIRS upper-tropospheric water vapor channel transmittance is compared between HIRS/2 and HIRS/3 (HIRS/3 minus HIRS/2, violet dashed line); note that the scale for the transmittance difference for HIRS is given at the top of the plot.

The MHS is a water vapor sounding instrument on board the NOAA polar-orbiting satellite series starting with NOAA-18 and the MetOp satellites of the European Organisation for the Exploitation of Meteorological Satellites (EUMETSAT) Polar System starting with MetOp-A. The channel specification of MHS is very similar to AMSU-B, but the central frequency of the lower-tropospheric humidity channel is changed from $183.31 \pm 7 \mathrm{GHz}$ on AMSU-B to $190.31 \mathrm{GHz}$ on MHS. The MHS instrument is a cross-tracking scanner with a swath width of approximately $1920 \mathrm{~km}$ and takes 90 measurements per scan line. The footprint at the nadir has a circular field of view with a diameter of $\sim 16 \mathrm{~km}$. MHS employs an absolute onboard calibration system like AMSU-B. The nominal noise equivalent temperatures are $0.50,0.41$, and $0.55 \mathrm{~K}$ for $183.31 \pm 1 \mathrm{GHz}$, $183.31 \pm 3 \mathrm{GHz}$, and $190.31 \mathrm{GHz}$ channels, respectively [note that John et al. (2012) found elevated noise for some of these channels-satellites].

The spectral characteristics of the three water vapor channels are compared between AMSU-B and MHS in terms of atmospheric transmittance to the top of the atmosphere from a pressure level. Figure 2 shows an example of the vertical profile of transmittance difference (MHS minus AMSU-B) for a given atmospheric profile. The vertical profiles of transmittance are almost the same for the upper-tropospheric $(183.31 \pm 1 \mathrm{GHz})$ and midtropospheric $(183.31 \pm 3 \mathrm{GHz})$ humidity channels. Although simulated brightness temperatures are smaller for MHS, brightness temperature differences are only $0.1-0.2 \mathrm{~K}$. The lower-tropospheric channel also shows a qualitatively similar pattern of transmittance difference. However, the magnitude of transmittance difference is much larger (e.g., Kleespies and Watts 2006; John et al. 2012). Correspondingly, differences of simulated brightness temperature increase $(\sim 0.6 \mathrm{~K})$.

We also examine the cases of HIRS upper-tropospheric humidity channels. The vertical profile of transmittance difference between HIRS $/ 3$ and HIRS/2 is presented with a dashed line in Fig. 2. Note that the scale for the HIRS case is given at the top of the plot. Transmittance differences between the two instruments are significant compared to the microwave counterpart. The uppertropospheric water vapor channel of HIRS $/ 3$ is sensitive to distinctly higher altitudes than that of HIRS/2, resulting in a substantial brightness temperature difference of $\sim 7 \mathrm{~K}$ (e.g., Shi and Bates 2011). Considering that the microwave radiometers (i.e., AMSU-B and MHS) probe nearly the same atmospheric layer, intersatellite calibration processes are expected to be more straightforward compared to the HIRS case. In addition, microwave observations are less prone to the clear-sky sampling bias (e.g., Buehler et al. 2008; Sohn and Bennartz 2008; John et al. 2011). As a result, the intercalibrated dataset of the $183.31 \pm 1 \mathrm{GHz}$ channel can be used to assess the stability of the merged HIRS upper-tropospheric humidity channel record for the HIRS transition period.

\section{Cloud clearing and limb correction}

The influence of clouds on the propagation of electromagnetic waves is generally insignificant in the microwave spectrum, implying that radiance measurements of the $183-\mathrm{GHz}$ water vapor absorption band are less prone to clear-sky sampling bias (e.g., Allan and Ringer 2003; Sohn and Bennartz 2008; John et al. 2011). However, the amount of radiation reaching spaceborne radiometers can be reduced because of the scattering by large ice particles in the presence of deep convective or precipitating clouds (e.g., Greenwald and Christopher 2002; Hong et al. 2005; Buehler et al. 2007). Therefore, cloud clearing methods are required to discard cloudcontaminated measurements that exhibit unreasonably low brightness temperatures.

Buehler et al. (2007) suggested an efficient method to remove cloud-contaminated measurements. The vertical 
distribution of weighting functions indicates that the $183.31 \pm 1 \mathrm{GHz}$ channel is sensitive to higher levels in the troposphere than the $183.31 \pm 7 \mathrm{GHz}(190.31 \mathrm{GHz}$ for MHS) channel (e.g., Buehler and John 2005). Because the atmospheric temperature generally decreases in the free troposphere, this means that brightness temperatures of the $183.31 \pm 1 \mathrm{GHz}$ channel should be colder than those of the $183.31 \pm 7 \mathrm{GHz}(190.31 \mathrm{GHz}$ for MHS) channel under clear-sky conditions. However, such a relationship could be reversed in the presence of convective or precipitating clouds because of the scattering effects of ice particles or rain drops (Buehler et al. 2007; John et al. 2011). Therefore, the negative brightness temperature difference [i.e., $183.31 \pm 7 \mathrm{GHz}(190.31 \mathrm{GHz}$ for MHS) $183.31 \pm 1 \mathrm{GHz}<0$ ] can be indicative of contamination by large ice particles or rain drops.

Radiative transfer simulations show that under clearsky conditions, the computed $183.31 \pm 1$ channel brightness temperature has a minimum value for each viewing angle. Because of the limb darkening effect, the brightness temperature decreases as the microwave radiometers scan away from the nadir. Since this minimum brightness temperature, which is a function of viewing angle, is considered to be warmer than the cloud-contaminated brightness temperature, a precomputed table of the viewing-angle-dependent minimum brightness temperatures (e.g., Buehler et al. 2007) can be used as a tool for determining the cloud contamination in conjunction with the brightness temperature difference between the $183.31 \pm 7 \mathrm{GHz}(190.31 \mathrm{GHz}$ for MHS $)$ and $183.31 \pm$ $1 \mathrm{GHz}$ channels. These two criteria suggested by Buehler et al. (2007) are applied to each measurement to identify cloud contamination.

In addition to the cloud filtering procedure, the limb darkening effect needs to be corrected in order to make a temporally and spatially averaged dataset from measurements with different satellite viewing angles. The scan angle dependence of observed brightness temperatures is generally adjusted by means of a linear multivariate regression. For the water vapor channels, however, an analytical relation derived by Soden and Bretherton (1993) can be employed to convert off-nadir brightness temperature into the nadir equivalent. Based on radiative transfer theory, Soden and Bretherton (1993) have shown that the clear-sky brightness temperature $\left(T_{B}\right)$ is related to the vertical mean of weighting-function-weighted relative humidity in the upper troposphere $(\bar{r})$ as follows:

$$
\ln \left(\frac{\bar{r} p_{0}}{\cos \theta}\right)=a+b T_{B}(\theta)
$$

where $p_{0}$ and $\theta$ denote a normalized base pressure [i.e., $p(T=240 \mathrm{~K}) / 300 \mathrm{mbar}$ ] and satellite zenith angle, respectively. The satellite viewing angle can be converted to satellite zenith angle through a geometric relation between them. The constants $a$ and $b$ are linear coefficients tuned to match detailed radiative transfer calculations. This logarithmic relationship originally developed for the $6.7-\mu \mathrm{m}$ channel can also be utilized for other channels located in the water vapor absorption band of both infrared and microwave spectra (e.g., Soden and Bretherton 1996; Buehler and John 2005; Chung et al. 2007). Note that values of the linear coefficients vary depending on the central wavelength of a given channel and the nature of associated spectral response function.

Since the $\bar{r}$ is not dependent on the satellite zenith angle in Eq. (1), the $\bar{r}$ retrieved from the brightness temperature with satellite zenith angle $\theta$ should be same as the nadir case. Therefore, the brightness temperature for satellite zenith angle $\theta$ can be related to the nadir brightness temperature as follows:

$$
T_{B}^{\mathrm{Nadir}}=T_{B}(\theta)+\log (\cos \theta) / b .
$$

Considering that the signs of both the numerator and denominator of the second term on the right-hand side of Eq. (2) are negative, the derived nadir brightness temperature is warmer than the original off-nadir value. The above equation can be employed for the limb correction for each $183-\mathrm{GHz}$ channel in conjunction with the corresponding value of $b$.

To determine $b$ for the limb correction, brightness temperatures are simulated for a multitude of viewing angles (and thus satellite zenith angles) as well as the nadir case with atmospheric profiles of the 60-level sampled European Centre for Medium-Range Weather Forecasts (ECMWF) dataset (Chevallier 2001) as input to a radiative transfer model (Buehler et al. 2005a). Figure 3 shows the brightness temperature difference between the nadir view and off-nadir cases for the $183.31 \pm 1 \mathrm{GHz}$ channel (top panel) and $183.31 \pm 3 \mathrm{GHz}$ channel (bottom panel) as a function of viewing angle. The vertical bars denote standard deviation at each viewing angle. As expected from the increased pathlength for the off-nadir cases, the simulated brightness temperature is generally lower than for the nadir case. However, deviations from Eq. (2) may occur because of surface influence or atmospheric temperature inversion in very dry conditions. Hence, these exceptional cases are excluded in the linear regression computations between the inverse of brightness temperature difference and $(\log \cos \theta)$. The computed values of $b$ are -0.1045 and -0.1146 for the $183.31 \pm$ $1 \mathrm{GHz}$ and $183.31 \pm 3 \mathrm{GHz}$ channels, respectively.

John et al. (2013b) have used simultaneous all angle collocations (SAACs) of both AMSU-B and MHS instruments to estimate scan-dependent biases. NOAA-15 

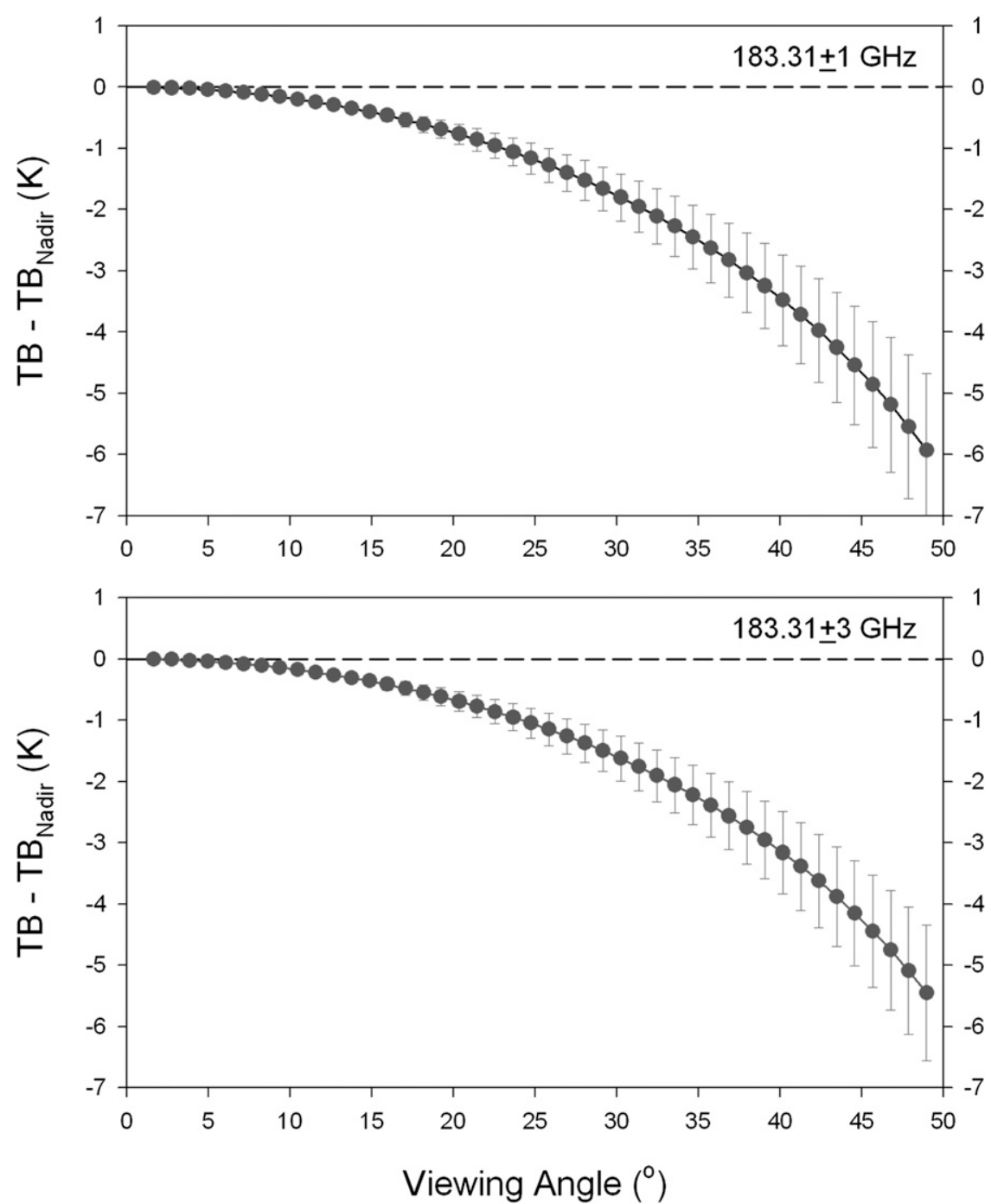

FIG. 3. Brightness temperature difference from the nadir view case as a function of satellite viewing angle for (top) $183.31 \pm 1 \mathrm{GHz}$ and (bottom) $183.31 \pm 3 \mathrm{GHz}$ channels. Closed circles and vertical bars denote mean and standard deviation, respectively. Brightness temperatures are simulated using atmospheric profiles of the 60-level sampled ECMWF dataset.

channels are found to be affected the most, mainly because of radio frequency interference (RFI) from onboard data transmitters (Atkinson 2001). The $183.31 \pm 3 \mathrm{GHz}$ channel of NOAA-15 shows the largest and time-varying biases; about 10 scan positions on the right edge of the scan suffer more than a 15-K bias during 2006-10. Measurements closer to nadir do not suffer from large biases except for the $183.31 \pm 3 \mathrm{GHz}$ and $183.31 \pm 7 \mathrm{GHz}$ channels on NOAA-15 and NOAA-16, respectively. They found the results are robust, in the sense that biases estimated for one satellite pair can be reproduced by double differencing biases of these satellites with a third satellite.

Equation (2) is applied to the cloud-filtered observed brightness temperatures with the statistically derived coefficient, and the resultant limb-corrected brightness temperatures are used to create spatially averaged datasets with a grid size of $0.25^{\circ}$ for each satellite with ascending and descending orbits separately. This daily dataset also includes information on viewing angle, observation time, and the number of pixels on each grid. In addition, the cloud-cleared and limb-corrected brightness temperatures are averaged onto monthly $1.5^{\circ}$ grids for each satellite with ascending and descending orbits separately.

\section{Adjustment of diurnal sampling difference related to satellite orbital drift}

Figure 4 compares the time series of equatorial local crossing time for the ascending node between 


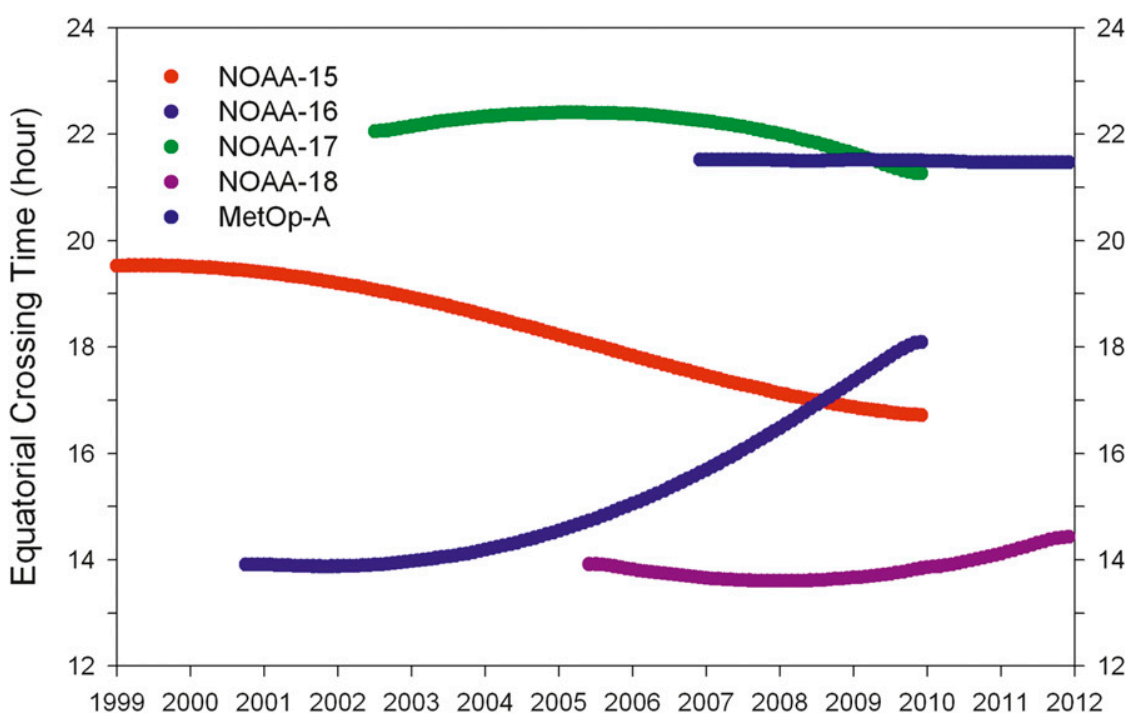

FIG. 4. The ascending node equatorial local crossing time for polar-orbiting satellites carrying AMSU-B (NOAA-15, -16, and -17) and MHS (NOAA-18 and MetOp-A).

polar-orbiting satellites carrying AMSU-B (NOAA-15, -16, and -17) and MHS (NOAA-18 and MetOp-A). Although polar-orbiting satellites tend to drift away from their original equatorial local crossing time at satellite launch, the comparison indicates that orbital drift is most significant for $N O A A-15$ and $N O A A-16$. Considering that $N O A A-15$ and NOAA-16 exhibit a distinct long-term trend of brightness temperature difference between ascending and descending orbits unlike the other more recent satellites (Fig. 1c), it is likely that the drift in the satellite orbit is hindering the long-term stability of satellite record and causing inconsistency between satellites (e.g., Mears et al. 2003; Jackson and Soden 2007). Since the long-term stability and consistency between satellites are essential requirements for climate monitoring, it is important to examine and adjust any biases induced by the satellite orbital drift.

The existence of a noticeable diurnal cycle of humidity in the tropical free troposphere means that observed brightness temperatures in the water vapor channels will be different depending on the local observation time (e.g., Chung et al. 2007, 2009; Eriksson et al. 2010). Hence, the difference of local observation time should be adjusted before merging measurements from different satellites into a long-term satellite record. The impact of an individual satellite orbital drift will be a spurious warming or cooling trend depending on the initial observation time and the sign of the time change (e.g., Mears et al. 2003; Jackson and Soden 2007; Mears and Wentz 2009).

Jackson and Soden (2007) suggested that the diurnal sampling bias due to the orbital drift of polar-orbiting satellites can be removed based on climate model simulations. By subsampling simulated HIRS/2 brightness temperatures from climate model output, the diurnal sampling bias in HIRS/2 observations were adjusted to the model daily mean. One limitation of using diurnal climatologies from climate model simulations is that the amplitude of the diurnal cycle in upper-tropospheric water vapor is strongly dependent upon the location of deep convection that has large year-to-year and regional dependences. In addition, climate models can have significant biases in simulating the diurnal cycle. To avoid these complications, we correct for the diurnal sampling bias of the $183-\mathrm{GHz}$ channel measurements using the Interim ECMWF Re-Analysis (ERA-Interim; Uppala et al. 2008; Dee et al. 2011), which has been shown to provide reasonable simulation of the diurnal cycle (e.g., Eriksson et al. 2010; Chung et al. 2013).

This study uses the ERA-Interim 6-hourly surface and profile dataset for the period 1999-2011 to simulate brightness temperatures of the $183-\mathrm{GHz}$ water vapor channels. Atmospheric profiles of temperature and water vapor and surface variables were inserted into a fast radiative transfer model [Radiative Transfer for the Television and Infrared Observation Satellite (TIROS) Operational Vertical Sounder (RTTOV); Hocking et al. 2011] to simulate the brightness temperature that would be observed by a satellite for given atmospheric conditions. The simulated brightness temperatures were subsampled at each grid point using the local measurement time of each satellite (i.e., Fig. 4), and compared with the corresponding diurnal mean. Figure 5 shows time series of the tropical mean of $183.31 \pm 1 \mathrm{GHz}$ channel 


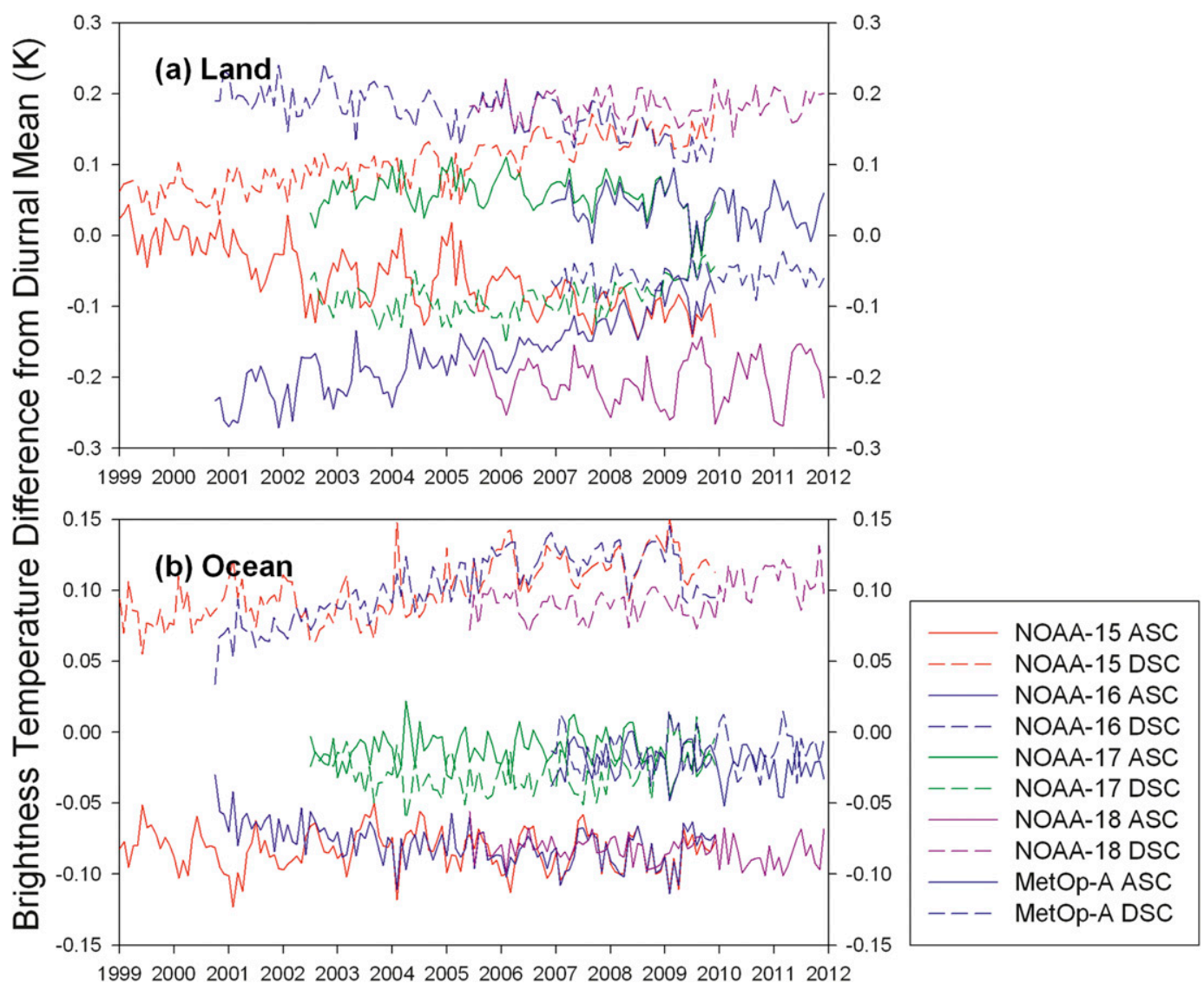

FIG. 5. Influence of satellite orbital drift on the long-term trend of $183.31 \pm 1 \mathrm{GHz}$ channel brightness temperatures simulated from ERA-Interim data over the tropics $\left(30^{\circ} \mathrm{S}-30^{\circ} \mathrm{N}\right)$ : (a) land and (b) ocean. Solid (dashed) lines denote domain average of the instantaneous ascending (descending) node brightness temperatures subtracted from the corresponding diurnal mean at each grid point.

brightness temperature difference from the diurnal mean for each satellite. Solid and dashed lines denote ascending and descending orbits, respectively. Given the distinct land-sea contrast in the diurnal cycle of humidity in the tropical free troposphere (e.g., Chung et al. 2007, 2009; Jackson and Soden 2007; Eriksson et al. 2010), time series are shown separately for land and ocean averages.

Given the time separation of $12 \mathrm{~h}$ between ascending and descending orbits, the sign of brightness temperature difference from the diurnal mean for an ascending orbit is different from that of a descending orbit with some exceptions over ocean. The trends of the brightness temperature difference are generally small for $N O A A-17, N O A A-18$, and $M e t O p-A$, which have relatively little drift in their observing times. By contrast, NOAA-15 (NOAA-16) exhibits a divergence (convergence) in the long-term trends between ascending and descending orbits. Similar patterns are produced for the $183.31 \pm 3 \mathrm{GHz}$ channel with larger magnitudes (not shown). These spurious trends are indicative of diurnal aliasing due to the satellite orbital drift.

Geographical distributions of the difference in brightness temperature between the instantaneous observation and the diurnal mean are examined for NOAA-16 in order to highlight the regions influenced by the drift in satellite orbit. The top panels of Fig. 6 illustrate the geographical distributions of brightness temperature difference averaged for the period 2001-02. The magnitude of the brightness temperature difference is large over the convectively active regions-that is, central Africa, South America, and the Maritime Continent-in agreement with previous studies (e.g., Chung et al. 2007, 2009; Schröder et al. 2009; Eriksson et al. 2010). Large magnitude is also found over the Tibetan Plateau, implying the surface influence associated with its high elevation. The difference from the diurnal mean is generally negligible over the ocean except for the oceanic intertropical convergence zone (ITCZ) regions. Because NOAA-16 drifts $3-4 \mathrm{~h}$ forward in time from its original 
[2001 2002]

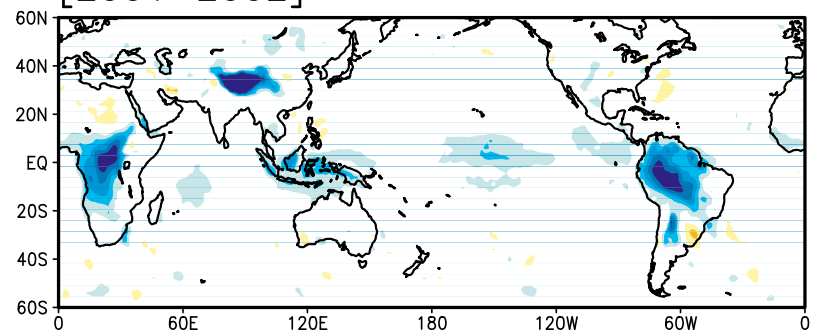

[2008 2009]

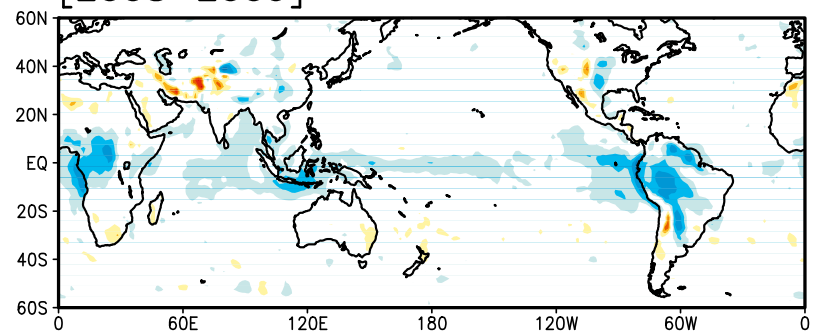

DSC
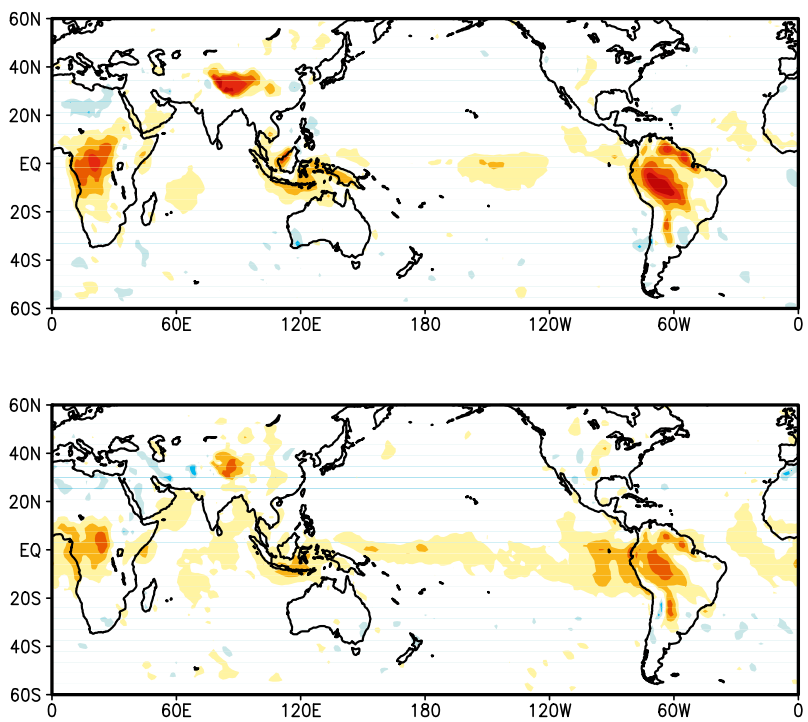

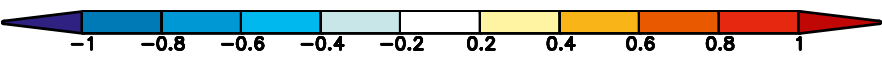

FIG. 6. Geographical distributions of the difference of simulated brightness temperature for (left) ascending node and (right) descending node from the corresponding diurnal mean for the NOAA-16 183.31 $\pm 1 \mathrm{GHz}$ channel. Two-year averages of the brightness temperature differences are compared between two separate periods to illustrate the temporal variation of diurnal sampling bias due to the orbital drift of NOAA-16: (top) 2001-02 and (bottom) 2008-09.

equatorial local crossing time, the magnitude of the brightness temperature difference reduces for the period 2008-09 (bottom panel). The magnitude can also be changed depending on the relation of shift with the diurnal-mean value.

Although the diurnal amplitude derived from the ERA-Interim simulations are likely underestimated (Eriksson et al. 2010; Chung et al. 2013), long-term trends qualitatively similar to satellite observations suggest that the difference between satellite-subsampled brightness temperature and the diurnal mean can be applied to the observed data to adjust the bias originated from the satellite orbital drift. The adjustment that needs to be applied to the observed brightness temperature can be expressed for a given longitude $(\lambda)$, latitude $(\phi)$, ascending or descending orbit $(n)$, channel $(c)$, satellite $(s)$, and time ( $t$, monthly time step) as

$$
\Delta T_{B}(\lambda, \phi, n, c, s, t)=\bar{T}_{B}(\lambda, \phi, c, s, t)-T_{B}(\lambda, \phi, n, c, s, t),
$$

where the first term on the right-hand side denotes the diurnal-mean brightness temperature. The brightness temperature adjustment tends to be nonlinear because of the nonlinearity of satellite orbital drift (Fig. 4) and the characteristics of the diurnal cycle (Jackson and Soden 2007). This adjustment also reduces the discrepancies between ascending and descending orbits stemming from the observation time difference.

The brightness temperature adjustment defined in Eq. (3) can be applied to each ascending and descending grid to create a diurnal-sampling bias-corrected brightness temperature dataset as follows:

$$
\begin{aligned}
T_{B}^{\mathrm{adj}}(\lambda, \phi, n, c, s, t)= & T_{B}^{\mathrm{obs}}(\lambda, \phi, n, c, s, t) \\
& +\Delta T_{B}(\lambda, \phi, n, c, s, t) .
\end{aligned}
$$

The first term on the right-hand side denotes a cloudfiltered, limb-corrected observed brightness temperature. Since the brightness temperature adjustment is determined with respect to the diurnal-mean value, the magnitude of required adjustment depends on the time relative to the diurnal phase. It is important to emphasize that this procedure only relies on the difference in brightness temperature $\left(\Delta T_{B}\right)$ between the satellite observing time and the full diurnal mean for that particular day and location. As such, it is not vulnerable to spurious trends that may exist in the reanalysis dataset itself.

The magnitude of the second harmonics is generally very small compared to that of the first harmonics for upper- and midtropospheric water vapor channels (e.g., Soden 2000; Tian et al. 2004; Chung et al. 2007). However, the diurnal cycles of surface temperature and 

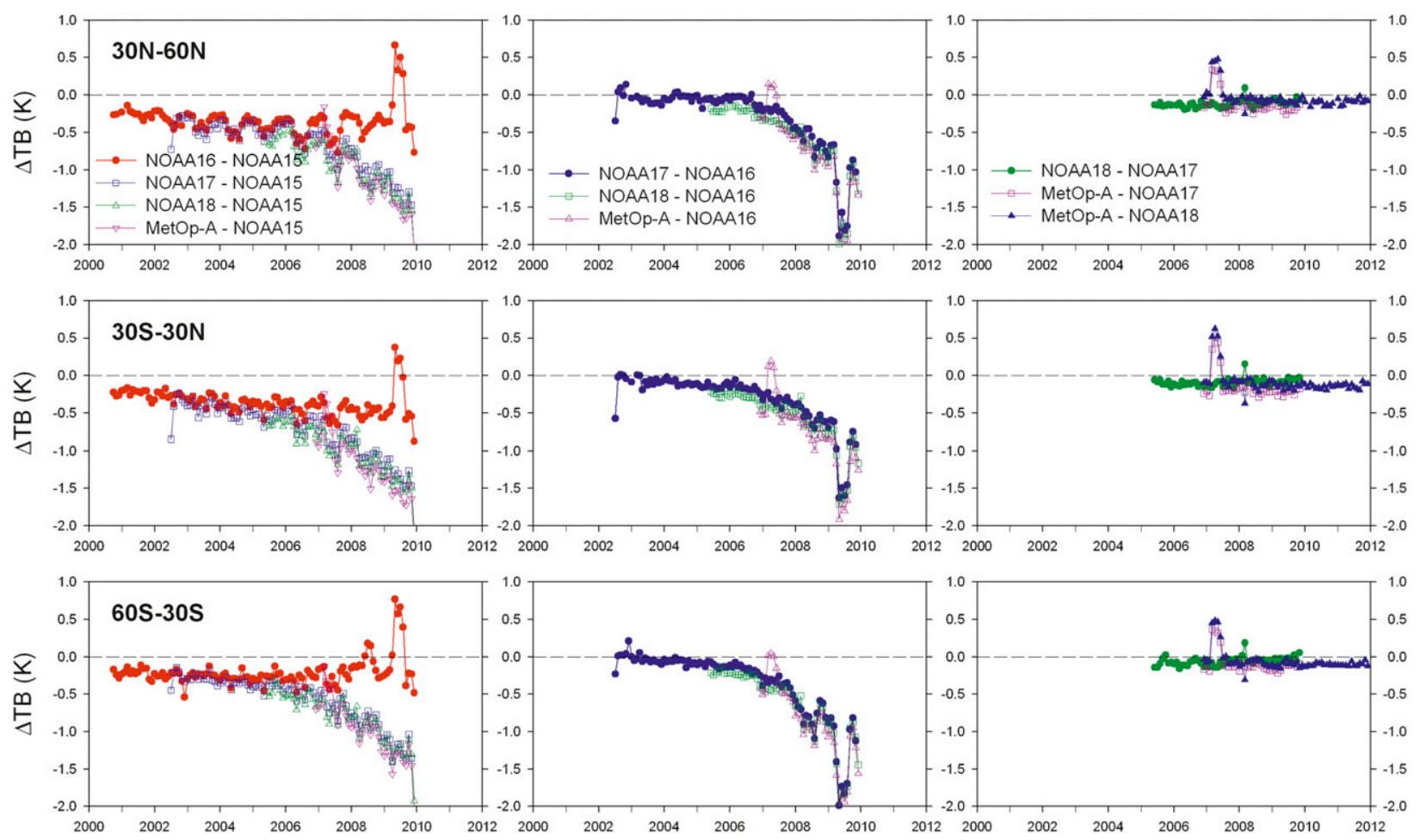

FIG. 7. Domain average of (left to right) the intersatellite differences of the diurnal sampling bias-corrected $183.31 \pm 1 \mathrm{GHz}$ channel brightness temperatures for ascending node: (top) $30^{\circ}-60^{\circ} \mathrm{N}$, (middle) $30^{\circ} \mathrm{S}-30^{\circ} \mathrm{N}$, and (bottom) $60^{\circ}-30^{\circ} \mathrm{S}$.

surface humidity may affect the diurnal cycle of the midtropospheric water vapor channel (i.e., $183.31 \pm 3 \mathrm{GHz}$ ) radiances over the high-elevated areas during dry seasons. In those circumstances, 6-hourly reanalysis dataset may not be sufficient to resolve the second harmonics. Thus, it should be noted that the diurnal correction based on 4-times-per-day sampling might be imperfect over the highelevated areas during dry seasons for the $183.31 \pm 3 \mathrm{GHz}$ channel.

\section{Intersatellite calibration}

Figure 7 compares the cloud-filtered, limb-corrected, and orbital-drift-corrected brightness temperatures between pairs of temporally overlapping satellites. Note that satellite pairs are constructed using monthly-mean, $1.5^{\circ}$ grid data. The domain-averaged intersatellite differences of $183.31 \pm 1 \mathrm{GHz}$ brightness temperature are shown for three separate regions $-30^{\circ}-60^{\circ} \mathrm{N}$ (top), $30^{\circ} \mathrm{S}-$ $30^{\circ} \mathrm{N}$ (middle), and $60^{\circ}-30^{\circ} \mathrm{S}$ (bottom) - and relative to three separate reference satellites-NOAA-15 (left), NOAA-16 (middle), and NOAA-17 (right). For recent satellites (right panel), small but systematic differences in the brightness temperature are apparent between $N O A A-17, N O A A-18$, and MetOp-A. The magnitude of the brightness temperature differences are within $0.3 \mathrm{~K}$ for most of the time span. Moreover, the temporal variations of brightness temperature differences are generally small, suggesting measurement consistency between these satellites. The larger differences in early 2007 seem to be caused by MetOp-A measurements, since the brightness temperature differences between NOAA-17 and NOAA-18 do not exhibit such an anomaly.

Time series of brightness temperature differences between NOAA-16 and three recent satellites exhibit a qualitatively similar pattern for all three domains (middle panels). The different pattern in early 2007 is attributable to MetOp- $A$. Measurements from NOAA-16 appear consistent with the other satellites up to mid2006, but the variations of brightness temperature differ substantially thereafter. The domain-averaged NOAA-16 brightness temperatures are warmer by up to $2 \mathrm{~K}$ than all other satellites. The consistency among the more recent satellites during this period (NOAA-17, NOAA-18, and MetOp-A) suggests that the NOAA-16 measurements are experiencing a calibration drift after mid-2006.

The left panels compare brightness temperature measurements of NOAA-15 with other satellite measurements. Similar variations of brightness temperature difference are found up to mid-2006. Once again, the divergence of the NOAA-15 and NOAA-16 pair from 

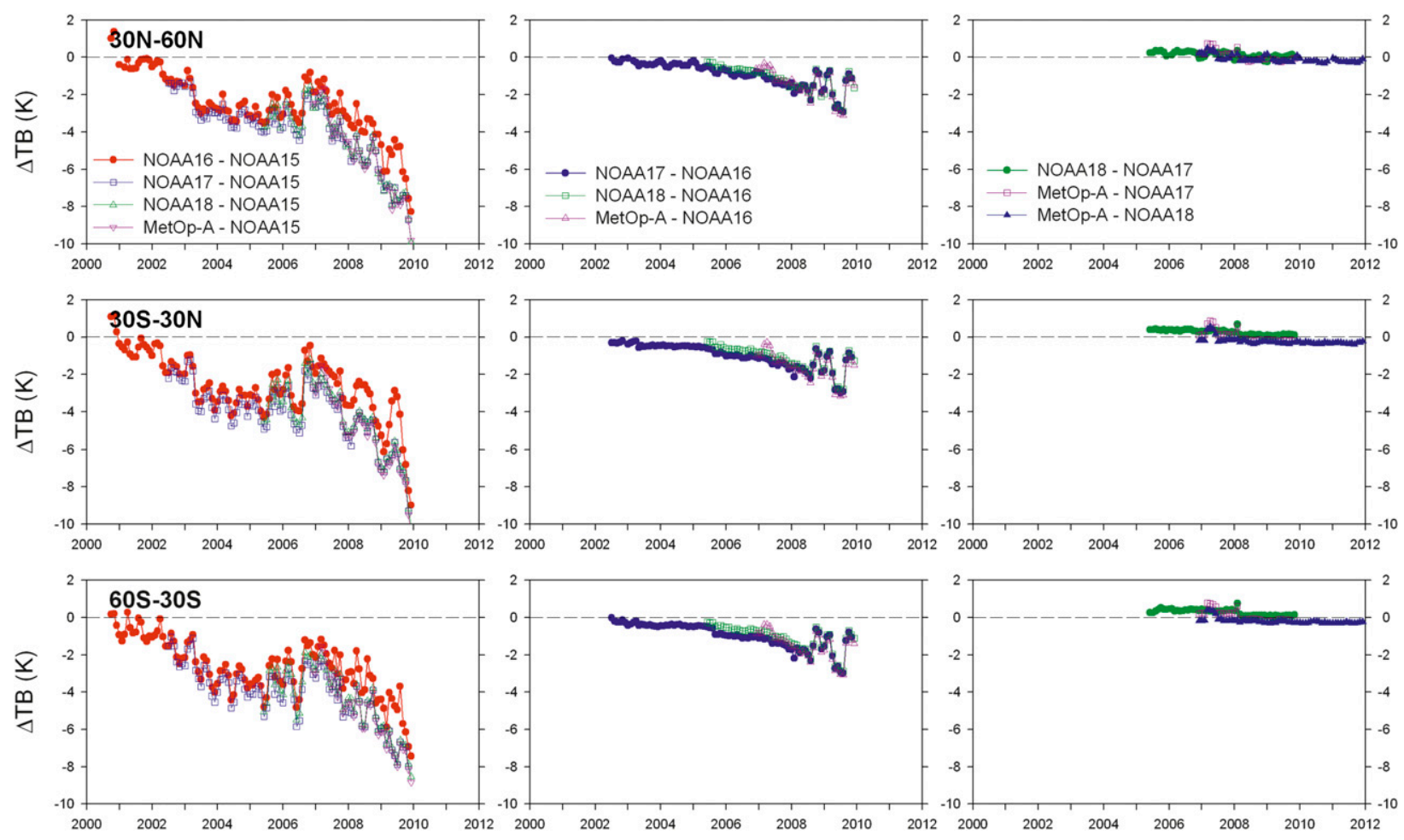

FIG. 8. As in Fig. 7, but for the $183.31 \pm 3 \mathrm{GHz}$ channel.

other satellites after mid-2006 is in line with the questionable quality of $N O A A-16$ revealed in the middle panels. Brightness temperatures of NOAA-15 are relatively stable with respect to other satellites for a couple of years, but then deviations from the other satellites increase nonlinearly. Similar conclusions are obtained from brightness temperature comparisons for the descending nodes (not shown). Brightness temperature measurements are consistent with each other among $N O A A-17, N O A A-18$, and MetOp-A. On the other hand, measurements from NOAA-15 and NOAA-16 degrade after the first several years.

For the $183.31 \pm 3 \mathrm{GHz}$ channel (Fig. 8), discrepancies in brightness temperature (monthly-mean, $1.5^{\circ}$ grid data) between satellites are larger than for the $183.31 \pm 1 \mathrm{GHz}$ channel. Nevertheless, the temporal variations of intersatellite brightness temperature difference are small between three recent satellites. In addition, NOAA-16 is consistent with other satellites for a slightly shorter period than for the $183.31 \pm 1 \mathrm{GHz}$ channel. By contrast, the brightness temperature difference between $N O A A$ 15 and the other satellites shows large fluctuations for its entire record, rendering the NOAA-15 record largely unusable for quantifying trends.

Buehler et al. (2005b) examined scan asymmetries in the NOAA-15, -16, and -17 AMSU-B observations for the $183.31 \pm 1$ and $183.31 \pm 3 \mathrm{GHz}$ channels, and found that the NOAA-15 $183.31 \pm 3 \mathrm{GHz}$ channel has significant asymmetry differences of up to $-9.67 \mathrm{~K}$. They also found asymmetry differences exceeding $1 \mathrm{~K}$ for the $183.31 \pm 1 \mathrm{GHz}$ channel of the same satellite. As a result, the large brightness temperature differences of NOAA-15 from other recent satellites shown in Figs. 7 and 8 could be caused by the asymmetric differences in the limb effect. This speculation suggests that the quality of NOAA-15 measurement might be improved if either the far limb data were to be removed or another correction was made to rectify the scan asymmetric bias.

The nominal channel characteristics of AMSU-B and MHS on board different satellites are similar. However, the onboard blackbody calibration systems-algorithms and the channel characteristics of sensor detectors may differ between satellites and the channel characteristics may change after launch (e.g., Cao et al. 2005, 2009; Jackson and Soden 2007). Intersatellite calibrations for polar-orbiting satellites have been conducted previously using the simultaneous nadir overpasses (SNO) method (e.g., Cao et al. 2005; Shi et al. 2008). Because the surface and atmospheric conditions are identical for SNO cases, discrepancies between similar instruments on board different satellites can be attributed to instrumentation differences rather than scene differences. However, SNOs for polar-orbiting satellites primarily occur over polar latitudes and the intercalibration results obtained 
from the polar SNOs may not represent atmospheric conditions of lower latitudes (e.g., Shi et al. 2008; Shi and Bates 2011; John et al. 2012). Because of the potential limitation of the SNO method, Shi and Bates (2011) suggested an alternative scene-temperature-dependent method that determines intersatellite biases based on matched zonal averages for overlapping satellites. Since the occurrences of SNO at the lower latitudes are infrequent for the polar-orbiting satellites with AMSU-B or MHS, the intersatellite brightness temperature differences are adjusted following the zonal-average method of Shi and Bates (2011) and John et al. (2012).

Given the stability of the MetOp-A equatorial crossing time and its consistency with $N O A A-17$ and NOAA-18, brightness temperature biases are adjusted using the Met $O p-A$ measurements as a benchmark. For pairs of MetOp-A/NOAA-18 and MetOp-A/NOAA-17, the zonal mean of brightness temperature differences is computed for $10^{\circ}$ latitude bins for the overlapping period that both satellite measurements are generally stable and consistent with each other (i.e., excluding early 2007 when MetOp- $A$ is suspect). Then, the obtained scene-dependent biases for MetOp-A-NOAA-18 and MetOp-A-NOAA-17 are applied to brightness temperatures of $N O A A-18$ and $N O A A-17$, respectively. NOAA-15 and NOAA-16 brightness temperatures are then adjusted based on the intercalibrated NOAA-17 measurements. More detailed discussion on the intercalibration methods and associated latitude dependence of the bias corrections are given in John et al. (2013a).

Time series of intercalibrated brightness temperatures averaged over the tropics are compared for the $183.31 \pm 1 \mathrm{GHz}$ (Fig. 9) and $183.31 \pm 3 \mathrm{GHz}$ (Fig. 10) channels. The comparisons are made separately for ascending (top) and descending (middle) nodes. Note that time series of the NOAA-15183.31 $\pm 3 \mathrm{GHz}$ channel is excluded in Fig. 10. Intersatellite differences are significantly reduced compared to Figs. 1 and 7. Moreover, the intercalibrated brightness temperatures do not show any distinct bias stemming from satellite orbital drift except for the period when the quality of $N O A A-15$ and NOAA-16 measurements is questionable.

The bottom panels show the time series of the difference between ascending and descending nodes. The diurnal adjustment and intercalibration substantially improves the consistency between the two nodes for most satellites. However, there remains a substantial drift $(\sim 0.2 \mathrm{~K})$ between the ascending and descending nodes for the NOAA-15183.31 $\pm 1 \mathrm{GHz}$ channel and for both channels on NOAA-16 after mid-2005. Considering that the orbital drift of the NOAA-15 satellite is less than one hour for the period 1999-2003, biases other than that due to the satellite orbital drift are likely responsible for these discrepancies. The corrected satellite observations also show an improved agreement between the two nodes in regions outside of the tropics (Fig. S1). Based upon this analysis, we exclude the NOAA-15 record completely from our analysis and limit NOAA-16 to the period prior to 2005 for both channels.

\section{Transformation to upper- and midtropospheric relative humidity}

After the intercalibration has been performed, we then transform the cloud-cleared and drift-corrected radiances to a corresponding measure of the upper- and midtropospheric relative humidity with respect to water (UTH and MTH, respectively) following Soden and Bretherton (1993, 1996).

In this study, UTH (MTH) is defined as the vertically averaged relative humidity weighted by the relative humidity Jacobian of the $183.31 \pm 1(183.31 \pm 3) \mathrm{GHz}$ channel. The radiance-to-humidity transformation follows the analytical relation represented in Eq. (1), and requires the information on the normalized base pressure $\left(p_{0}\right)$ and the channel-specific linear coefficients $(a$ and $b)$. The normalized base pressure is determined using the climatology of the ERA-Interim dataset (Uppala et al. 2008; Dee et al. 2011). To obtain the linear coefficients, we computed relative humidity Jacobians as well as brightness temperatures for each profile equatorward of $60^{\circ}$ latitude from the 60-level sampled ECMWF dataset (Chevallier 2001). Then, simulated brightness temperature is compared with the corresponding value of $\ln \left(\bar{r} p_{0} / \cos \theta\right)$, where $\bar{r}$ denotes UTH (MTH) for the $183.31 \pm 1(183.31 \pm 3) \mathrm{GHz}$ channel. The linear regression coefficients for the $183.31 \pm 1 \mathrm{GHz}$ channel are $a=27.6251$ and $b=-0.0977$. For the $183.31 \pm 3 \mathrm{GHz}$ channel, the regression coefficients are $a=29.5526$ and $b=-0.0991$. Because of the difference in regression formulation, the values of $b$ are different slightly from those for the limb correction. The correlation coefficients are -0.96 for both channels. Thus, UTH and MTH can be inferred from the observed 183-GHz brightness temperatures as follows:

$$
\begin{aligned}
\mathrm{UTH} & =\frac{\cos \theta}{p_{0}} e^{\left(27.6251-0.0977 T_{B}^{183.31 \pm 1}\right)} \\
\mathrm{MTH} & =\frac{\cos \theta}{p_{0}} e^{\left(29.5526-0.0991 T_{B}^{183.31 \pm 3}\right)} .
\end{aligned}
$$

Figure 11 displays the geographical distribution of UTH and MTH averaged for the period 2001-11. The distribution of upper-tropospheric humidity reflects the major features of the large-scale circulation, with high 

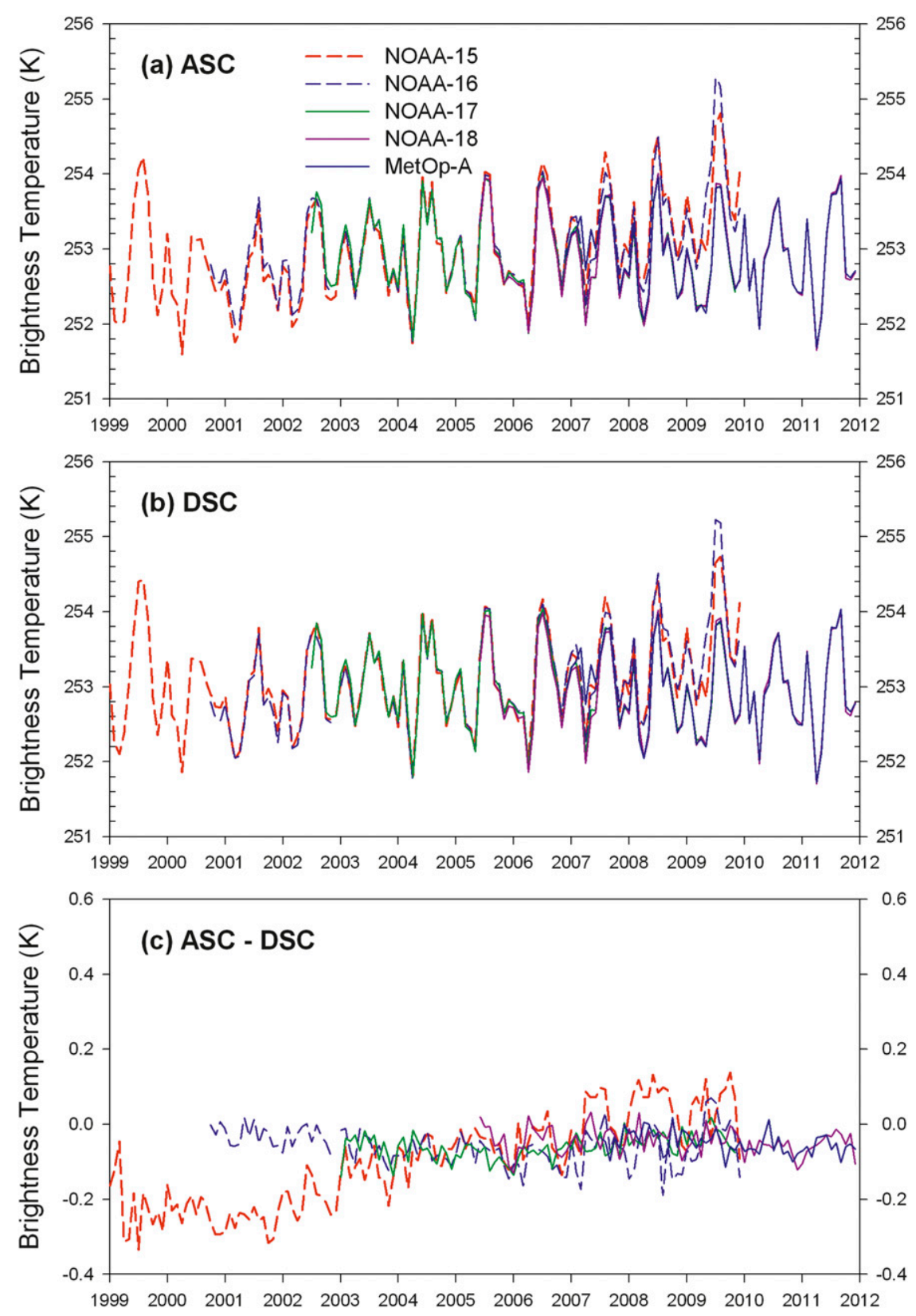

FIG. 9. Time series of the diurnal sampling bias-corrected, intersatellite-calibrated monthlymean $183.31 \pm 1 \mathrm{GHz}$ channel brightness temperatures averaged over the tropics. Time series are separately created for the (a) ascending and (b) descending node, and (c) the difference between ascending and descending nodes.

values over convectively active regions and low values in regions of large-scale descent. The MTH is generally greater than the UTH, implying a decrease in relative humidity with increasing altitude in the free troposphere. However, the locations of moist and dry regions are generally similar to those for UTH. Since the spatial patterns of UTH and MTH are closely associated with the large-scale circulation, their trends can be useful indicators of changes in the large-scale circulation (e.g., Chung et al. 2011).

Reanalysis datasets and climate model simulations are frequently used to examine the long-term variations of upper-tropospheric moisture and their attribution to internal variability, natural forcing, and anthropogenic forcing. Regarding this aspect, it is a prerequisite to ensure that reanalysis datasets and climate model simulations can 

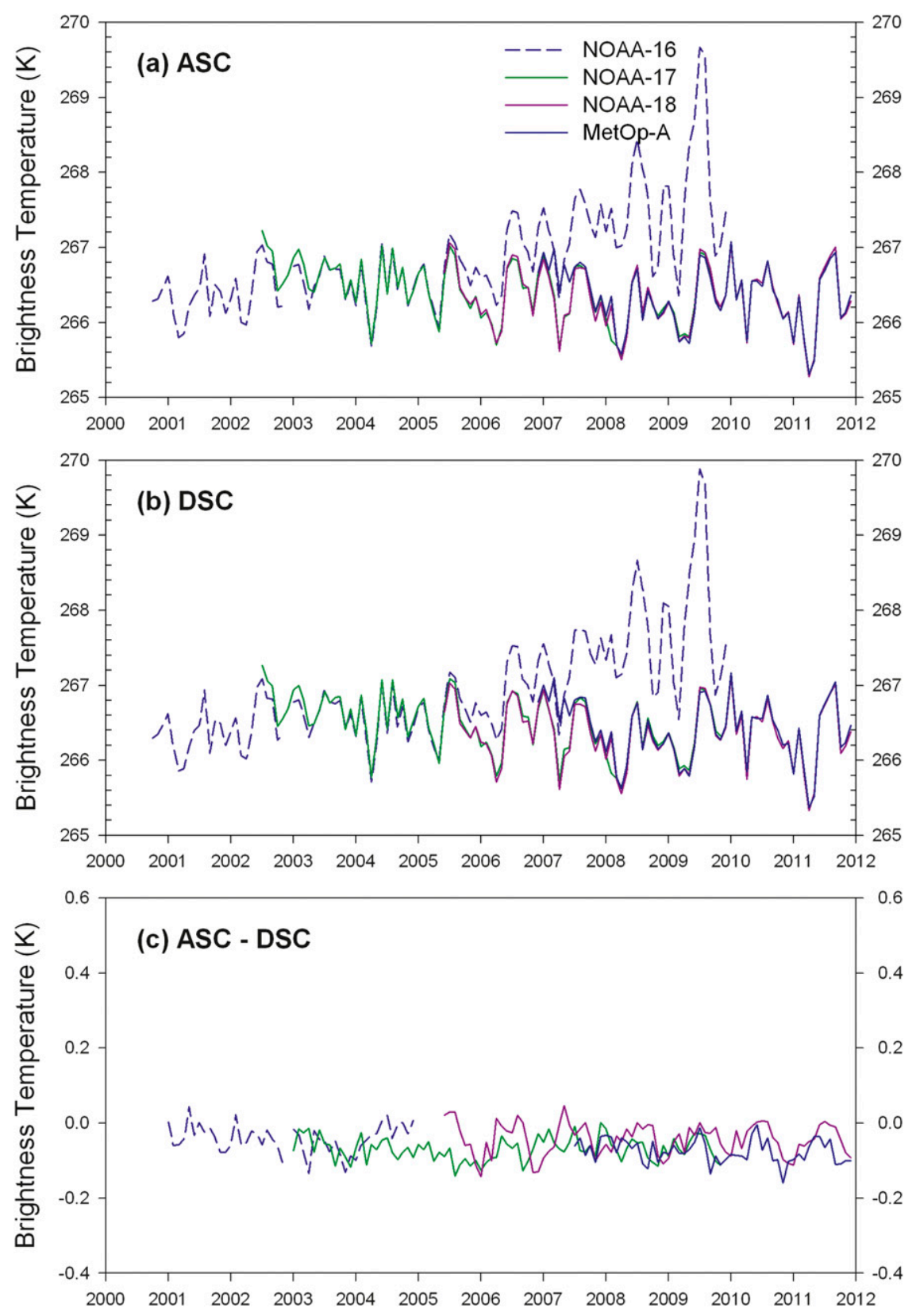

FIG. 10. As in Fig. 9, but for the $183.31 \pm 3 \mathrm{GHz}$. Time series for $N O A A-15$ is excluded because of its unreasonably large biases and instability.

reproduce the long-term variations determined from satellite observations (e.g., Soden et al. 2005). Previous studies have noted substantial deficiencies in the humidity trends (e.g., Trenberth et al. 2001; Allan et al. 2002, 2004; Paltridge et al. 2009; John et al. 2011). Thus, constructing a long-term UTH dataset from the bias-corrected, intersatellite-calibrated $183.31 \pm 1 \mathrm{GHz}$ channel brightness temperature will facilitate assessment of the long-term variations depicted in the reanalysis datasets and climate model simulations.

\section{Summary and conclusions}

To generate a homogenized, long-term, upper- and midtropospheric humidity dataset, we examined the microwave water vapor radiances measured from AMSU-B and MHS instruments on board polar-orbiting satellites. These instruments have three water vapor channels sensitive to humidity in the upper troposphere $(183.31 \pm 1 \mathrm{GHz})$, midtroposphere $(183.31 \pm 3 \mathrm{GHz})$, and lower troposphere $(183.31 \pm 7 \mathrm{GHz}$ for AMSU-B 

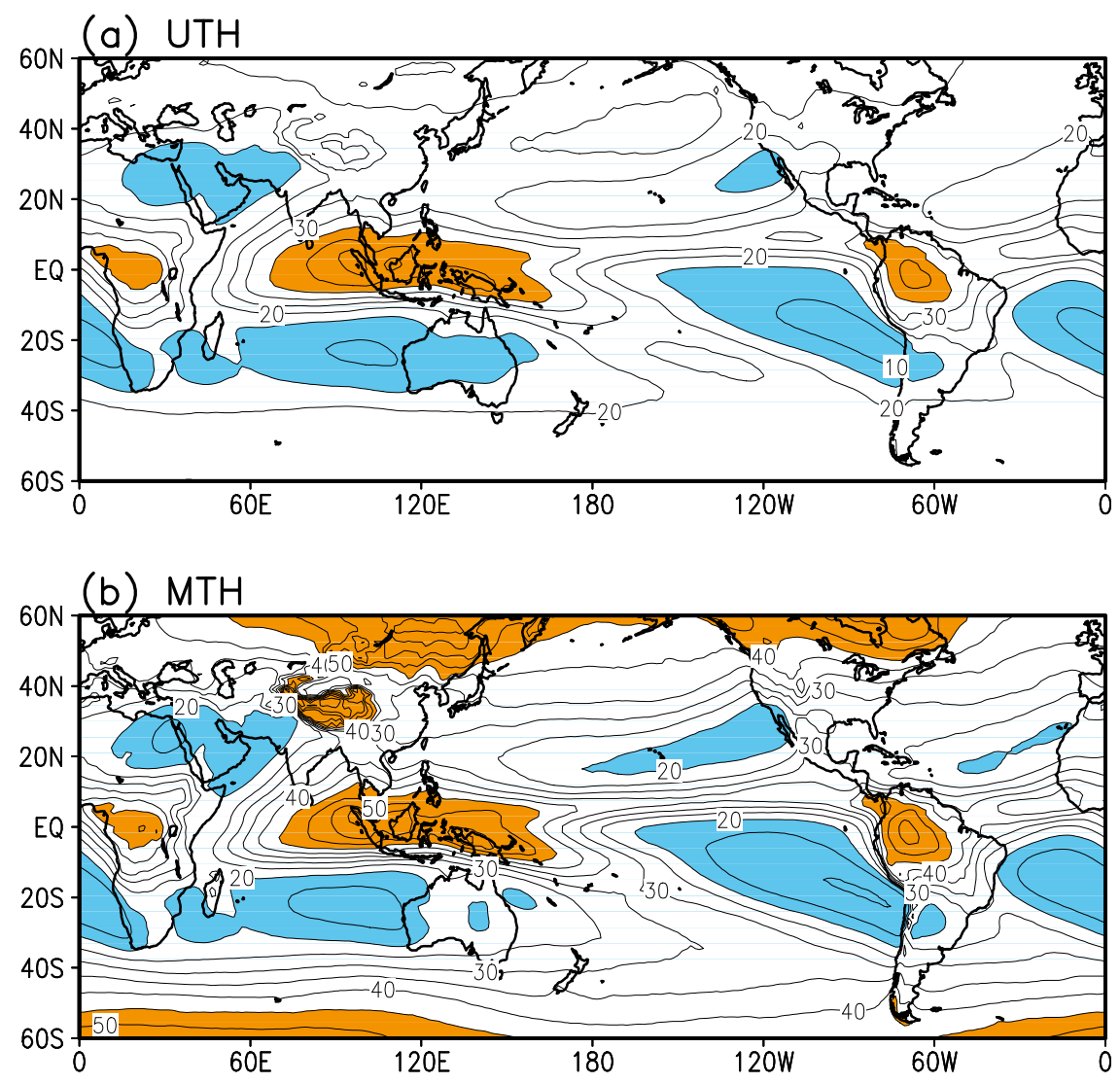

FIG. 11. Geographical distribution of (a) upper-tropospheric relative humidity (\%) and (b) midtropospheric relative humidity (\%) averaged for the period 2001-11.

and $190.31 \mathrm{GHz}$ for MHS). The characteristics of these water vapor channels are almost identical between AMSU-B (NOAA-15, -16, and -17) and MHS (NOAA18 and $M e t O p-A)$.

Measurements contaminated by clouds were discarded using a cloud-filtering algorithm (Buehler et al. 2007). The variation of brightness temperatures due to the difference in scan angle was also corrected by converting an off-nadir measurement into the value for the nadir condition based on the analytical relation between humidity in the free troposphere and water vapor channel brightness temperature (Soden and Bretherton 1993, 1996). Then, daily and monthly gridded datasets were created for each satellite with ascending and descending orbits separately.

The uncorrected brightness temperatures measured from these satellites exhibit large differences and divergences in long-term trend that are largely attributable to satellite orbital drift and intercalibration differences. As the satellite observations gradually change in local time because of orbital drift, the observed brightness temperatures become warmer or colder depending on the relative location to the peak time in the diurnal cycle.
Brightness temperature adjustments were developed to correct the diurnal sampling bias using brightness temperatures simulated from ERA-Interim products, and applied to the cloud-cleared, limb-corrected measurements. Although biases due to other error sources such as instrument degradation, differences in spatiotemporal sampling, and presumable underestimation of the diurnal cycle in reanalysis datasets might still remain, the consistency and quantitative agreement between satellites was significantly improved through our correction procedures.

NOAA polar-orbiting satellites have carried AMSU$B$ as well as HIRS for the transition period from HIRS/2 to HIRS/3. Thus, the constructed microwave dataset (especially the $183.31 \pm 1 \mathrm{GHz}$ channel) can be used to examine the long-term stability of the merged HIRS record, and thereby facilitate the continuation of the long-term monitoring capabilities of upper-tropospheric water vapor provided by HIRS/2 observations. In addition, given that microwave measurements are less affected by clouds compared to the longer HIRS infrared measurements, improved spatiotemporal coverage of the constructed microwave dataset will help assess the 
reliability of reanalysis datasets and climate models in depicting the distribution and variation of water vapor in the free troposphere.

Acknowledgments. We thank four anonymous reviewers for their constructive and valuable comments, which led to an improved version of the manuscript. AMSU-B and MHS data were provided by the NOAA Comprehensive Large Array-Data Stewardship System (CLASS). ERA-Interim products were obtained from the ECMWF data server. This study was supported by a grant from the NOAA Climate Program Office. Viju John was supported by the U.K. JWCRP and the Joint DECC/Defra Met Office Hadley Centre Climate Programme (GA01101). We thank David Parker for his valuable comments.

\section{REFERENCES}

Allan, R. P., and M. A. Ringer, 2003: Inconsistencies between satellite estimates of longwave cloud forcing and dynamical fields from reanalyses. Geophys. Res. Lett., 30, 1491, doi:10.1029/ 2003GL017019.

— A. Slingo, and V. Ramaswamy, 2002: Analysis of moisture variability in the European Centre for Medium-Range Weather Forecasts 15-year reanalysis over the tropical oceans. J. Geophys. Res., 107, 4230, doi:10.1029/2001JD001132.

- M. A. Ringer, and A. Slingo, 2003: Evaluation of moisture in the Hadley Centre climate model using simulations of HIRS water-vapour channel radiances. Quart. J. Roy. Meteor. Soc., 129, 3371-3389.

,-- J. A. Pamment, and A. Slingo, 2004: Simulation of the Earth's radiation budget by the European Centre for MediumRange Weather Forecasts 40-year reanalysis (ERA40). J. Geophys. Res., 109, D18107, doi:10.1029/2004JD004816.

Atkinson, N. C., 2001: Calibration, monitoring and validation of AMSU-B. Adv. Space Res., 28, 117-126.

Bates, J. J., and D. L. Jackson, 2001: Trends in upper tropospheric humidity. Geophys. Res. Lett., 28, 1695-1698.

—, X. Wu, and D. L. Jackson, 1996: Interannual variability of upper-tropospheric water vapor band brightness temperature. J. Climate, 9, 427-438.

— D. L. Jackson, F.-M. Bréon, and Z. D. Bergen, 2001: Variability of tropical upper tropospheric humidity 1979-1998. J. Geophys. Res., 106 (D23), 32271-32281.

Buehler, S. A., and V. O. John, 2005: A simple method to relate microwave radiances to upper tropospheric humidity. J. Geophys. Res., 110, D02110, doi:10.1029/2004JD005111.

— - P. Eriksson, T. Kuhn, A. von Engeln, and C. Verdes, 2005a: ARTS, the atmospheric radiative transfer simulator. J. Quant. Spectrosc. Radiat. Transfer, 91, 65-93.

—- M. Kuvatov, and V. O. John, 2005b: Scan asymmetries in AMSU-B data. Geophys. Res. Lett., 32, L24810, doi:10.1029/ 2005 GL024747.

,-- , T. R. Sreerekha, V. O. John, B. Rydberg, P. Eriksson, and J. Notholt, 2007: A cloud filtering method for microwave upper tropospheric humidity measurements. Atmos. Chem. Phys., 7, 5531-5542.

$\longrightarrow,-$, V. O. John, M. Milz, B. J. Soden, D. L. Jackson, and J. Notholt, 2008: An upper tropospheric humidity data set from operational satellite microwave data. J. Geophys. Res., 113, D14110, doi:10.1029/2007JD009314.

Cao, C., H. Xu, J. Sullivan, L. McMillin, P. Ciren, and Y.-T. Hou, 2005: Intersatellite radiance biases for the High-Resolution Infrared Radiation Sounders (HIRS) on board NOAA-15, -16, and -17 from simultaneous nadir observations. J. Atmos. Oceanic Technol., 22, 381-395.

_- M. Goldberg, and L. Wang, 2009: Spectral bias estimation of historical HIRS using IASI observations for improved fundamental climate data records. J. Atmos. Oceanic Technol., 26, 1378-1387.

Chevallier, F., 2001: Sampled databases of 60-level atmospheric profiles from the ECMWF analyses. EUMETSAT/ECMWF SAF Programme Research Rep. 4, 27 pp.

Chung, E.-S., B. J. Sohn, J. Schmetz, and M. Koenig, 2007: Diurnal variation of upper tropospheric humidity and its relations to convective activities over tropical Africa. Atmos. Chem. Phys., 7, 2489-2502.

$\longrightarrow,-$, and 2009: Diurnal variation of outgoing longwave radiation associated with high cloud and UTH changes from Meteosat-5 measurements. Meteor. Atmos. Phys., 105, 109119.

—_, B. J. Soden, B.-J. Sohn, and J. Schmetz, 2011: Modelsimulated humidity bias in the upper troposphere and its relation to the large-scale circulation. J. Geophys. Res., 116, D10110, doi:10.1029/2011JD015609.

,,$-- \ldots$, and $—, 2013$ : An assessment of the diurnal variation of upper tropospheric humidity in reanalysis data sets. J. Geophys. Res. Atmos., 118, 3425-3430, doi:10.1002/jgrd.50345.

Dee, D. P., and Coauthors, 2011: The ERA-Interim reanalysis: Configuration and performance of the data assimilation system. Quart. J. Roy. Meteor. Soc., 137, 553-597.

Eriksson, P., B. Rydberg, M. Johnston, D. P. Murtagh, H. Struthers, S. Ferrachat, and U. Lohmann, 2010: Diurnal variations of humidity and ice water content in the tropical upper troposphere. Atmos. Chem. Phys., 10,11519-11533.

Greenwald, T. J., and S. A. Christopher, 2002: Effect of cold clouds on satellite measurements near $183 \mathrm{GHz}$. J. Geophys. Res., 107, 4170, doi:10.1029/2000JD000258.

Held, I. M., and B. J. Soden, 2000: Water vapor feedback and global warming. Annu. Rev. Energy Environ., 25, 441-475.

Hocking, J., P. Rayer, R. Saunders, M. Matricardi, A. Geer, and P. Brunel, 2011: RTTOV v10 users guide. NWP SAF Doc. NWPSAF-MO-UD-023, EUMETSAT, 92 pp.

Hong, G., G. Heygster, J. Miao, and K. Kunzi, 2005: Detection of tropical deep convective clouds from AMSU-B water vapor channels measurements. J. Geophys. Res., 110, D05205, doi:10.1029/2004JD004949.

Jackson, D. L., and B. J. Soden, 2007: Detection and correction of diurnal sampling bias in HIRS/2 brightness temperatures. J. Atmos. Oceanic Technol., 24, 1425-1438.

John, V. O., and S. A. Buehler, 2004: The impact of ozone lines on AMSU-B radiances. Geophys. Res. Lett., 31, L21108, doi:10.1029/2004GL021214.

_ , and B. J. Soden, 2007: Temperature and humidity biases in global climate models and their impact on climate feedbacks. Geophys. Res. Lett., 34, L18704, doi:10.1029/2007GL030429.

- G. Holl, R. P. Allan, S. A. Buehler, D. E. Parker, and B. J. Soden, 2011: Clear-sky biases in satellite infrared estimates of upper tropospheric humidity and its trends. J. Geophys. Res., 116, D14108, doi:10.1029/2010JD015355.

—_ - - S. A. Buehler, B. Candy, R. W. Saunders, and D. E. Parker, 2012: Understanding intersatellite biases of 
microwave humidity sounders using global simultaneous nadir overpasses. J. Geophys. Res., 117, D02305, doi:10.1029/ 2011JD016349.

—, R. P. Allan, W. Bell, S. A. Buehler, and A. Kottayil, 2013a: Assessment of intercalibration methods for satellite microwave humidity sounders. J. Geophys. Res. Atmos., 118, 49064918, doi:10.1002/jgrd.50358.

, G. Holl, N. Atkinson, and S. A. Buehler, 2013b: Monitoring scan asymmetry of microwave humidity sounding channels using simultaneous all angle collocations (SAACs). J. Geophys. Res. Atmos., 118, 1536-1545, doi:10.1002/jgrd.50154

Kleespies, T. J., and P. Watts, 2006: Comparison of simulated radiances, Jacobians and linear error analysis for the Microwave Humidity Sounder and the Advanced Microwave Sounding Unit-B. Quart. J. Roy. Meteor. Soc., 132, 3001-3010.

Mears, C. A., and F. J. Wentz, 2009: Construction of the Remote Sensing Systems V3.2 atmospheric temperature records from the MSU and AMSU microwave sounders. J. Atmos. Oceanic Technol., 26, 1040-1056.

_ M. C. Schabel, and F. J. Wentz, 2003: A reanalysis of the MSU channel 2 tropospheric temperature record. J. Climate, 16, 3650-3664

Paltridge, G., A. Arking, and M. Pook, 2009: Trends in middle- and upper-level tropospheric humidity from NCEP reanalysis data. Theor. Appl. Climatol., 98, 351-359.

Schröder, M., M. König, and J. Schmetz, 2009: Deep convection observed by the Spinning Enhanced Visible and Infrared Imager on board Meteosat 8: Spatial distribution and temporal evolution over Africa in summer and winter 2006. J. Geophys. Res., 114, D05109, doi:10.1029/2008JD010653.

Sherwood, S. C., R. Roca, T. M. Weckwerth, and N. G. Andronova, 2010: Tropospheric water vapor, convection, and climate. Rev. Geophys., 48, RG2001, doi:10.1029/2009RG000301.
Shi, L., and J. J. Bates, 2011: Three decades of intersatellitecalibrated High-Resolution Infrared Radiation Sounder upper tropospheric water vapor. J. Geophys. Res., 116, D04108, doi:10.1029/2010JD014847.

, — - and C. Cao, 2008: Scene radiance-dependent intersatellite biases of HIRS longwave channels. J. Atmos. Oceanic Technol., 25, 2219-2229.

Soden, B. J., 2000: The diurnal cycle of convection, clouds, and water vapor in the tropical upper troposphere. Geophys. Res. Lett., 27, 2173-2176.

— , and F. P. Bretherton, 1993: Upper tropospheric relative humidity from the GOES $6.7 \mu \mathrm{m}$ channel: Method and climatology for July 1987. J. Geophys. Res., 98 (D9), 16669-16688. , and - , 1996: Interpretation of TOVS water vapor radiances in terms of layer-average relative humidities: Method and climatology for the upper, middle, and lower troposphere. J. Geophys. Res., 101 (D5), 9333-9343, doi:10.1029/ 96JD00280.

D. L. Jackson, V. Ramaswamy, M. D. Schwarzkopf, and $X$. Huang, 2005: The radiative signature of upper tropospheric moistening. Science, 310, 841-844.

Sohn, B.-J., and R. Bennartz, 2008: Contribution of water vapor to observational estimates of longwave cloud radiative forcing. J. Geophys. Res., 113, D20107, doi:10.1029/2008JD010053.

Tian, B., B. J. Soden, and X. Wu, 2004: Diurnal cycle of convection, clouds, and water vapor in the tropical upper troposphere: Satellite versus a general circulation model. J. Geophys. Res., 109, D10101, doi:10.1029/2003JD004117.

Trenberth, K. E., D. P. Stepaniak, J. W. Hurrell, and M. Fiorino, 2001: Quality of reanalyses in the tropics. J. Climate, 14, 1499-1510.

Uppala, S., and Coauthors, 2008: Towards a climate data assimilation system: Status update of ERA-Interim. ECMWF Newsletter, No. 115, ECMWF, Reading, United Kingdom, 12-18. 